\title{
Kualitas Audit Berdasarkan Time Budget Pressure dan Pengalaman
}

\author{
Iin Rosini \\ dosen00014@unpam.ac.id, \\ Universitas Pamulang \\ Dani Rahman Hakim \\ danirahmanhak@gmail.com, \\ Universitas Pamulang
}

\begin{abstract}
This study aims to examine the effect of auditor experience and time budget pressure on audit quality. Research approach with quantitative methods. The final sample used was 78 auditors from public accounting firms (KAP) throughout the DKI Jakarta area. Data collection instruments using questionnaires on a scale of 1 to 5. Data analysis method is multiple linear regression with the help of SPSS application version 22. The results of this study indicate that the auditor's experience is proven to affect audit quality. Time budget pressure also affects audit quality as well. Based on that, the auditor should increase his flight hours in carrying out inspection tasks and train himself to manage the time budget pressure that the company demands
\end{abstract}

Keyword : Audit Quality, Experience, Time Budget Pressure

\begin{abstract}
ABSTRAK
Penelitian ini bertujuan untuk menguji pengaruh pengalaman auditor dan time budget pressure terhadap kualitas audit. Pendekatan penelitian dengan metode kuantitatif. Sampel final yang digunakan adalah sebanyak 78 auditor dari kantor akuntan publik (KAP) se-wilayah DKI Jakarta. Instrumen pengumpulan data menggunakan kuesioner dengan skala 1 hingga 5. Metode analisis data yang digunakan yakni regresi linier berganda dengan bantuan aplikasi SPSS versi 22. Hasil penelitian ini menunjukan bahwa pengalaman auditor terbukti mempengaruhi kualitas audit. Begitupula dengan time budget pressure juga mempengaruhi kualitas audit. Berdasarkan hal itu, auditor sebaiknya menambah jam terbangnya dalam melakukan tugas pemeriksaan serta melatih diri untuk mengelola time budget pressure yang dituntut perusahaan.
\end{abstract}

Kata Kunci : Kualitas Audit, Pengalaman, Time Budget Pressure

\section{PENDAHULUAN}

Intensitas persaingan yang tinggi cenderung membuat perusahaan berimprovisasi salah satunya dengan melakukan praktek creative accounting. Peran auditor memegang kedudukan yang cukup sentral dalam memastikan kredibilitas laporan keuangan suatu perusahaan. Auditor dituntut mampu mendeteksi segenap praktik creative accounting serta fraud yang dilakukan 
perusahaan untuk menghasilkan kualitas audit yang mumpuni. Dengan demikian, audit memainkan peran penting sebagai mekanisme eksternal tata kelola perusahaan yang pada intinya tujuan audit itu sendiri adalah untuk menjamin bahwa tidak ada kesalahan dalam pelaporan keuangan yang disebabkan fraud atau kesalahan lain (Xiao et al., 2020).

Beragam skandal akuntansi terjadi karena rendahnya kualitas audit yang dilakukan para auditor. Misalnya saja skandal keuangan PT Kimia Farma, Garuda Indonesia, hingga Jiwasraya yang tidak dapat terlepas dari minimnya kualitas audit atas laporan keuangan perusahaanperusahaan tersebut. Investor bahkan publik dapat tersesatkan oleh laporan keuangan karena mereka cenderung mengambil keputusan berdasarkan laporan yang telah dibuat auditor (Ayuningtyas \& Pamudji, 2012). Penting bagi seorang auditor untuk menjaga independensi dan profesonalitasnya agar hasil audit benar-benar dapat dipercaya para pengguna informasi laporan keuangan.

Kualitas audit akan lebih maksimal apabila auditor dapat mengantisipasi gangguan time budget pressure. Berdasarkan penelitian Suryo (2017), Cita Dewi \& Ramantha (2019), Desi \& Dini (2014), Siagian \& Meutia (2016), Arisinta (2013), Anugrah (2017), Aisyah \& Sukirman (2015), Yaniartha (2013), Nurhayati (2015), Elizabeth \& Laksito (2017), dan Andreas (2016) yang menyatakan bahwa kualitas audit dipengaruhi oleh time budget pressure, suatu kondisi dimana terdapat tekanan waktu anggaran yang mengharuskan auditor segera menyelesaikan pekerjaan auditnya.

Nyaris tidak ditemukan adanya perbedaan hasil penelitian dalam kaitannya dengan pengaruh time budget pressure terhadap kualitas audit. Penelitian-penelitian terdahulu cenderung mendukung bahwa kualitas audit dapat menurun apabila terjadi time budget pressure. Padahal, semestinya time budget pressure dapat diantisipasi dengan upaya-upaya yang efektif oleh auditor. Khususnya auditor di KAP-KAP DKI Jakarta yang notabene secara pendidikan dan pengalaman relatif dianggap lebih mumpuni.

Aspek lain yang dianggap sebagai penentu kualitas auditor adalah pengalaman auditor itu sendiri. Penelitian Andreas (2016) menjelaskan bahwa kemungkinan terjadinya kesalahan auditor dalam melaporkan audit adalah karena kapabilitas teknis seperti pendidikan, pengalaman, profesionalisme, independensi, dan perilaku auditor itu sendiri. Kapabilitas teknis dalam konteks ini merupakan aspek yang cenderung terikat pada norma atau kode etik auditor serta dapat diperoleh secara simultan. Artinya, baik itu auditor baru maupun yang sudah berpengalaman cenderung bisa mendapatkan kesempatan yang sama dalam meningkatkan keempat aspek kapabilitas teknis tersebut.

Berbeda dengan kapabilitas teknis, aspek pengalaman auditor menjadi suatu modal yang tidak dapat diperoleh semua auditor. Hanya auditor yang sudah lama berkecimpung dalam dunia auditing saja yang mendapatkannya. Bahkan, aspek pengalaman dijadikan sebagai acuan utama untuk menyatakan kredibilitas seorang auditor. Berdasarkan hal itu, penelitian ini berupaya mengeksplorasi lebih jauh sebesar apa pengaruh pengalaman terhadap kualitas audit. Dalam konteks ini, beberapa penelitian telah membuktikan bahwa pengalaman berpengaruh signifikan terhadap kualitas audit, diantarannya dari Yaniarta (2013), Agustin (2013), Wardhani (2015), Putri \& Laksito (2013), Aisyah \& Sukirman (2015), Nurhayati (2015), Trihapsari \& Anisyakurlillah (2016), serta Oktarini \& Ramantha (2016). 
Namun demikian, dalam penelitian Futri \& Juliarsa (2014), Purnamasari \& Hernawati (2017), dan Wulan \& Primasari (2017) tidak ditemukan pengaruh signifikan antara pengalaman terhadap kualitas audit. Hal ini menunjukan bahwa masih terdapat research gap dalam kaitannya dengan hubungan pengalaman auditor dengan kualitas auditnya. Artinya, pengalaman auditor dapat mempengaruhi atau tidak mempengaruhi kualitas audit. Berdasarkan hal tersebut penelitian ini bermaksud untuk membuktikan kembali seberapa besar pengaruh pengalaman auditor terhadap kualitas hasil auditnya.

\section{TINJAUAN PUSTAKA}

\section{Konsep Kualitas Audit}

Kualitas audit didefinisikan sebagai kemungkinan bahwa salah saji material dalam laporan keuangan dapat terdeteksi dan dilaporkan oleh auditor. Selain itu, kualitas audit tersebut ditentukan oleh independensi dan kompetensi auditor (Xiao et al., 2020). Proses dari kualitas audit tersebut dapat disimplifikasi ke dalam aktivitas mendeteksi, menyesuaikan, dan melaporkan salah saji material, serta mengupayakan agar mendapatkan kualitas audit yang terbaik (Xiao et al., 2020).

Para pengguna laporan keuangan cenderung mengambil keputusan berdasarkan laporan yang dibuat auditor (Ayuningtyas \& Pamudji, 2012). Kualitas audit dipahami sebagai kondisi seorang auditor menemukan dan melaporkan ketidaksesuaian laporan keuangan yang diaudit sesuai dengan prinsip yang ditentukan (Ningsih, 2013).

Ada kaitan antara kualitas audit dengan reputasi auditor itu sendiri. Dalam konteks ini menurut (Asante-Appiah, 2019) auditor cenderung merespon resiko lingkungan, sosial, dan tata kelola perusahaan dalam melakukan audit. Perusahaan yang aspek sosial dan tata kelolanya bereputasi baik, cenderung akan memiliki hasil audit yang berkualitas. Hal ini menunjukan bahwa kualitas audit juga sangat berkaitan erat dengan tata kelola serta reputasi perusahaan.

Pengukuran kualitas audit cenderung beragam. Penelitian Sun et al (2020) misalnya, menggunakan 5 rasio untuk mengukur kualitas audit yakni violate, absda, stdwca, mao, dan restate. Violate adalah ukuran apabila perusahaan teridentifikasi melakukan penipuan atau manipulasi laporan keuangan. Absda merupakan singkatan dari absolut value of performanceadjudsted abnormal accruals atau nilai absolut dari akrual abnormal yang disesuaikan dengan kinerja. STDWCA merupakan singkatan dari the standard deviation of abnormal working capital accruals atau standar deviasi akrual modal kerja abnormal. Mao adalah ukuran apabila perusahaan terbukti memodifikasi hasil audit. Sementara restate adalah ketika perusahaan menurunkan laporan laba audited ke tahun sebelumnya.

Adapun apabila mengadopsi Ningsih (2013) dan Muhsyi (2013) terdapat 3 indikator yang dapat digunakan untuk mengukur kualitas hasil audit yaitu kesesuaian hasil pemeriksaaan dengan standar audit, keandalan dan manfaat laporan audit, dan kualitas laporan hasil audit. Indikator-indikator ini pada awalnya mengadopsi pandangan De Angelo (1981).

\section{Konsep Time Budget Pressure}

Menurut Maulina et al (2010), keberadaan batas waktu mengakibatkan adanya konflik karena waktu yang ditentukan untuk suatu pekerjaan audit terlewati, sehingga dapat mengganggu kualitasnya. Time budget pressure atau yang juga diartikan sebagai tekanan 
anggaran waktu merupakan tekanan yang muncul berdasarkan keterbatasan sumber daya yang dimiliki untuk menyelesaikan suatu pekerjaan (Ningsih, 2013). Adapun Suprianto (2009) menyatakan bahwa merencanakan waktu audit yang baik sangat penting bagi seorang auditor. Apabila auditor dapat mengalokasikan waktunya dengan baik, maka hasil pekerjaannya dapat dimaksimalkan.

Alasan terjadinya time budget pressure menurut Willet \& Page (1996) salah satunya adalah karena metode audit yang dikembangkan relatif sudah lebih baik yang memungkinkan penyelesaian waktu audit lebih cepat. Level kompetensi auditor juga sudah dikembangkan, dengan demikian fee untuk audit menjadi lebih besar bagi perusahaan. Mengantisipasi terlalu besarnya fee tersebut, perusahaan cenderung mengetatkan time audit budget.

Time budget pressure menurut Yaniartha (2013) merupakan suatu kondisi dimana auditor dituntut melakukan efisiensi anggaran waktu yang telah disusun karena adanya pembatasan waktu dan anggaran yang sangat ketat. Pemahaman lainnya yakni time budget pressure dapat berkaitan dengan prilaku disfungsional auditor karena adanya tekanan waktu tersebut. Mengacu pada Yaniartha (2013), dan Prasita \& Adi (2007), terdapat 3 indikator yang dapat digunakan untuk mengukur time budget pressure yaitu pemanfaatan waktu audit, tingkat efisiensi anggaran waktu, dan kemungkinan terjadinya penurunan kualitas audit yang dihasilkan karena adanya time budget pressure.

Penelitian Suryo (2017), Cita Dewi \& Ramantha (2019), Desi \& Dini (2014), Siagian $\&$ Meutia (2016), Arisinta (2013), Anugrah et al (2017), Aisyah \& Sukirman (2015), Yaniartha (2013), Nurhayati (2015, Elizabeth \& Laskito (2017), dan Andreas (2016) menyatakan bahwa time budget pressure dapat mempengaruhi kualitas audit. Berdasarkan hal tersebut, hipotesis pertama dalam penelitian ini adalah sebagaimana berikut, H1 : Time budget pressure berpengaruh terhadap kualitas audit.

\section{Konsep Pengalaman Auditor}

Pengalaman auditor menjadi salah satu aspek yang disyaratkan dalam standar profesional akuntan publik (Samsi et al., 2013). Dalam konteks ini, Nasution (2013) menjustifikasi bahwa pengalaman merupakan pengetahuan atau keahlian yang diperoleh berdasarkan suatu peristiwa melalui pengamatan atau partisipasi langsung. Atas dasar itu, semakin banyak dan semakin kompleks tugas yang diterima oleh seorang auditor maka akan menambah dan memperluas wawasan auditor atas pekerjaan yang digelutinya.

Menurut Suraida (2005), pengalaman auditor diperoleh selama melakukan proses pengauditan laporan keuangan. Baik itu yang dilihat dari aspek lamanya waktu, maupun kuantitas penugasan yang ditangani. Auditor yang berpengalaman cenderung memiliki kemampuan yang lebih mumpuni untuk mendeteksi kekeliruan serta kecurangan dalam suatu laporan keuangan. Di samping itu, auditor tersebut juga dapat memberi penjelasan yang lebih komprehensif atas temuannya tersebut.

Pekerjaan sebagai auditor menuntut keahlian dan profesionalisme tinggi. Keahlian tersebut tidak hanya didapatkan melalui pendidikan formal, tetapi juga melalui pengalaman. Semakin luas pengalamannya, semakin terampil auditor tersebut, sehingga semakin sempurna pola fikir dan tindakan untuk mencapai tujuannya (Ayuningtyas \& Pamudji, 2012). Indikator yang dapat digunakan untuk mengukur pengalaman auditor berdasarkan penelitian Susetyo 
(2009), dan Ayuningtyas \& Pamudji (2012) yakni lamanya bekerja, banyaknya tugas pemeriksaan, dan penguasaan terhadap pekerjaan serta peralatannya.

Penelitian dari Yaniartha (2013), Agustin (2013), Wardhani et al (2015), Putri \& Laksito (2013), Aisyah \& Sukirman (2015), Nurhayati (2015), Trihapsari \& Anisyakurlillah (2016), dan Oktarini \& Ramantha (2016) membuktikan bahwa pengalaman auditor dapat mempengaruhi kualitas audit. Berdasarkan hal tersebut, hipotesis kedua dalam penelitian adalah sebagai berikut, H2 : Pengalaman auditor berpengaruh terhadap kualitas audit.

\section{METODE PENELITIAN}

Penelitian ini menggunakan metode kuantitatif dengan analisis regresi linier. Pengukuran data menggunakan kuesioner yang disebar kepada 130 auditor di KAP wilayah Jakarta. Dari seluruh kuesioner yang disebarkan, 96 diantarannya dikembalikan untuk kemudian hanya diambil sebanyak 78 sebagai sampel final. Kuesioner untuk mengukur kualitas audit disusun berdasarkan pendapat Ningsih (2013), dan Muhsyi (2013) dengan indikator berupa kesesuaian hasil pemeriksaan dengan standar audit, keandalan dan manfaat laporan audit, dan kualitas laporan hasil audit. Pengukuran time budget pressure mengadaptasi penelitian Yaniartha (2013) dan Prasita \& Adi (2007) dengan indikator pemanfaatan waktu audit, tingkat efisiensi anggaran waktu, dan penurunan kualitas audit. Sementara pengukuran pengalaman auditor mengadaptasi penelitian Susetyo (2009) dan Ayuningtyas \& Pamudji (2012) dengan indikator lama bekerja, kuantitas tugas pemeriksaan, serta penguasaan pekerjaan dan peralatan.

\section{Uji Instrumen}

Hasil pengujian instrumen dalam penelitian ini dilakukan dengan memperbandingkan nilai pearson correlation hasil output SPSS dengan nilai $r$ table pada total responden 78 dengan degree of freedom 2 taraf signifikansi 0,05 sehingga menjadi 0,223. Apabila nilai pearson correlation lebih besar dari $r$ table maka item pertanyaan kuesioner dinyatakan valid. Hasil pengujian validitas instrumen kuesioner dapat terlihat dari Tabel 1, 2, serta 3 berikut ini :

Tabel 1. Hasil Uji Validitas Variabel Pengalaman Auditor

\begin{tabular}{cccc}
\hline Code & Pearson Correlation & $\mathrm{r}_{\text {table }}$ & Remark \\
\hline Q1 & 0,637 & 0,223 & Valid \\
Q2 & 0,584 & 0,223 & Valid \\
Q3 & 0,647 & 0,223 & Valid \\
Q4 & 0,722 & 0,223 & Valid \\
Q5 & 0,624 & 0,223 & Valid \\
Q6 & 0,702 & 0,233 & Valid \\
Q7 & 0,621 & 0,233 & Valid \\
Q8 & 0,503 & 0,233 & Valid \\
\hline
\end{tabular}

Sumber : data yang diolah

Tabel 1 merupakan hasil dari pengujian seluruh item pertanyaan kuesioner yang mengukur variabel pengalaman auditor. Hasilnya menunjukan bahwa 8 item pertanyaan 
kuesioner memiliki nilai lebih dari $r$ table sehingga seluruh item pertanyaan tersebut valid secara statistik.

Tabel 2. Hasil Uji Validitas Variabel Time Budget Pressure

\begin{tabular}{cccc}
\hline Code & Pearson Correlation & $\mathrm{r}_{\text {table }}$ & Remark \\
\hline Q1 & 0,546 & 0,223 & Valid \\
Q2 & 0,733 & 0,223 & Valid \\
Q3 & 0,745 & 0,223 & Valid \\
Q4 & 0,825 & 0,223 & Valid \\
Q5 & 0,734 & 0,223 & Valid \\
Q6 & 0,487 & 0,233 & Valid \\
Q7 & 0,763 & 0,233 & Valid
\end{tabular}

Sumber : data yang diolah

Tabel 2 merupakan hasil dari pengujian seluruh item pertanyaan kuesioner yang mengukur variabel time budget pressure. Hasilnya menunjukan bahwa 7 item pertanyaan kuesioner yang disusun berdasarkan indikatornya itu memiliki nilai lebih dari $r$ table sehingga seluruh item pertanyaan tersebut dinyatakan valid secara statistik.

Tabel 3. Hasil Uji Validitas Variabel Kualitas Audit

\begin{tabular}{cccc}
\hline Code & Pearson Correlation & $\mathrm{r}_{\text {table }}$ & Remark \\
\hline Q1 & 0,690 & 0,223 & Valid \\
Q2 & 0,573 & 0,223 & Valid \\
Q3 & 0,688 & 0,223 & Valid \\
Q4 & 0,724 & 0,223 & Valid \\
Q5 & 0,630 & 0,223 & Valid \\
Q6 & 0,747 & 0,223 & Valid \\
Q7 & 0,718 & 0,223 & Valid \\
Q8 & 0,667 & 0,223 & Valid \\
Q9 & 0,531 & 0,223 & Valid \\
Q10 & 0,462 & 0,223 & Valid \\
\hline
\end{tabular}

Sumber : data yang diolah

Hasil pengujian validitas instrumen variabel kualitas audit juga menunjukan 10 item pertanyaan valid secara statistik karena lebih besar dari $r$ tabel. Adapun pengujian reliabilitas instrumen untuk seluruh variabel penelitian dilakukan dengan melihat nilai Cronbach Alpha. Apabila nilai Cronbach Alpha lebih besar dari 0,6, maka instrumen dianggap reliabel. Hasilnya dapat terlihat dari Tabel 4 sebagaimana berikut : 
Tabel 4. Hasil Uji Reliabilitas Instrumen

\begin{tabular}{lccl}
\hline \multicolumn{1}{c}{ Variable } & $\begin{array}{c}\text { Cronbach Alpha } \\
(\alpha)\end{array}$ & N of Items & Remark \\
& 0,812 & 8 & Reliable \\
Pengalaman Audit & 0,797 & 7 & Reliable \\
Time Budget Pressure & 0,967 & 10 & Reliable \\
Kualitas Hasil Audit & & & \\
\hline
\end{tabular}

Sumber : data yang diolah

\section{HASIL DAN PEMBAHASAN}

Siklus penelitian dilakukan selama 8 bulan, dari Februari hingga September 2019. Responden yang diteliti adalah para auditor yang bekerja di KAP wilayah Jakarta yang telah berizin untuk memberikan jasa akuntan publik. Para auditor KAP wilayah Jakarta dipilih sebagai responden karena mereka cenderung lebih banyak mendapatkan pekerjaan audit ketimbang para aditor di daerah lainnya. Karakteristik responden terdiri dari junior auditor, senior auditor, manajer, dan partner yang menangani jasa audit laporan keuangan, jasa audit khusus, jasa atestasi, jasa review laporan keuangan, serta jasa perpajakan.

\section{Hasil Statistik Deskriptif}

Hasil analisis statistik deskriptif dalam penelitian ini dapat terlihat dari tabel berikut ini

Tabel 5. Hasil Statistik Deskriptif Variabel

\begin{tabular}{llllll}
\hline \multicolumn{1}{c}{ Variable } & N & Mean & Std Dev. & Min & Max \\
\hline Pengalaman Auditor & 78 & 31,69 & 3,683 & 24 & 40 \\
Time Budget Pressure & 78 & 28,91 & 4,252 & 20 & 35 \\
Kualitas Hasil Audit & 78 & 41,93 & 4,417 & 32 & 50 \\
\hline
\end{tabular}

Sumber : data yang diolah

Nilai mean untuk pengalaman auditor apabila dikategorikan ke dalam distribusi frekuensinya, tergolong pada kategori yang sedang. Sementara time budget pressure berada pada kategori cukup tinggi, dan kualitas audit berada pada kategori sedang. Pemahaman dari angka statistik ini yaitu pengalaman di kalangan auditor KAP Jakarta cenderung merata karena banyaknya auditor-auditor baru. Besarnya time budget pressure dinilai karena tingginya persaingan jasa audit di Jakarta, sehingga nilai kualitas auditnya juga cenderug berada pada kategori sedang yang merata.

\section{Hasil Pengujian Hipotesis}

Hasil penelitian ini dapat terlihat dari tabel sebagaimana berikut : 
Tabel 6. Rangkuman Hasil Pengujian Hipotesis

\begin{tabular}{lllll}
\hline & $\mathrm{B}$ & $\mathrm{T}$ & Sig. & \\
\hline (Constant) & 11.368 & 3.601 & .001 & $* * *$ \\
Pengalaman Auditor & .530 & 5.330 & .000 & $* * *$ \\
$\begin{array}{l}\text { Time Budget } \\
\text { Pressure }\end{array}$ & -.477 & 5.541 & .000 & $* * *$ \\
$\mathrm{R}^{2}$ & .567 & & & \\
Adj R $^{2}$ & .556 & & & \\
F-Stat & 49.148 & & & \\
F (Prob) & 0.000 & &
\end{tabular}

Sumber : data yang diolah

Berdasarkan Tabel 6, didapatkan persamaan regresi dalam penelitian ini adalah sebagai berikut :

$$
Y=11,368+0,53-0,47+3,157
$$

Persamaan regresi menunjukan bahwa besaran pengaruh pengalaman auditor terhadap kualitas audit bersifat positif sebesar 0,53 yang artinya apabila terjadi kenaikan sebesar 1 poin dari variabel pengalaman auditor, maka akan meningkatkan nilai kualitas audit sebesar 0,53 poin. Nilai negatif 0,47 pada variabel time budget pressure menunjukan bahwa apabila terjadi peningkatan sebesar 1 poin dalam variabel time budget pressure maka nilai kualitas audit akan turun sebesar 0,47 poin. Nilai konstanta menunjukan bahwa apabila pengalaman dan time budget pressure adalah 0 , maka nilai kualitas audit adalah sebesar 11,367. Sementara nilai 3,157 mengindikasikan nilai eror dari kemampuan prediksi persamaan regresi ini.

Dilihat dari nilai sig pada Tabel 6, hasil uji hipotesis pertama dan kedua dinyatakan diterima karena nilai sig dari koefisien regresi pengalaman auditor dan time budget pressure terhadap kualitas audit sama-sama lebih kecil dari 0,05. Artinya, baik itu pengalaman auditor maupun time budget pressure sama-sama signifikan mempengaruhi kualitas audit.

Hasil pengujian hipotesis pertama menunjukan pengalaman auditor berpengaruh terhadap kualitas audit. Secara empiris, indikator pengalaman auditor yang nilai cukup dominan yakni banyaknya tugas pemeriksaan yang diperoleh. Indikator ini kontribusinya tergolong paling tinggi, sehingga implikasinya adalah bahwa kualitas audit sangat ditentukan oleh banyaknya tugas pemeriksaan yang pernah dijalani oleh auditor tersebut.

Lamanya auditor bekerja tidak serta merta menjamin kualitas hasil auditnya mumpuni. Tetapi, meskipun auditornya cenderung masih lebih muda, tetapi apabila tugas pemeriksaan yang dijalaninya sudah lebih banyak, relatif dapat menghasilkan audit yang lebih berkualitas. Semakin banyak mendapatkan tugas untuk melakukan audit, maka setiap tantangan dan hal-hal baru akan tergali sehingga dapat memperkaya pengalaman auditor. 
Pengalaman auditor yang berpengaruh terhadap kualitas audit dalam penelitian ini sejalan dengan penelitian-penelitian dari Yaniartha (2013), Agustin (2013), Wardhani et al (2015), Putri \& Laksito (2013), Aisyah \& Sukitrman (2015), Nurhayati (2015), Trihapsari \& Anisyakurillah (2016), dan Oktarini \& Ramantha (2016). Namun, hasil penelitian ini tidak sejalan dengan penelitian dari Futri \& Juliarsa (2014), Purnamasari \& Hernawati (2017), dan Wulan \& Primasari (2017).

Kondisi ini menunjukan bahwa karakteristik responden cukup menentukan hasil penelitian. Dalam konteks ini, responden penelitian ini dengan penelitian-penelitian terdahulu yang hasilnya sejalan memiliki karakteristik yang relatif mirip. Atas dasar itu, kemampuan generalisasi dari penelitian ini hanya sebatas populasi, tidak memiliki kemampuan transferability ke objek penelitian lain. Sehingga, pengaruh pengalaman auditor terhadap kualitas auditnya di KAP-KAP lain perlu mendapat penetrasi penelitian baru.

Adapun pengaruh time budget pressure yang signifikan terhadap kualitas audit dalam penelitian ini menunjukan bahwa auditor-auditor di KAP Jakarta belum dapat secara maksimal mengelola waktu pelaksanaan auditnya di tengah deadline yang ditentukan perusahaan. Faktanya, time budget pressure masih menjadi faktor yang menurunkan kualitas audit. Temuan ini sejalan dengan hasil penelitian yang dilakukan Suryo (2017), Desi \& Dhini (2014), Aisyah \& Sukirman (2015), Yaniartha (2013), Nurhayati (2015), dan Andreas (2016). Kondisi ini menunjukan bahwa meskipun auditor-auditor di KAP Jakarta yang notabene secara pengalaman cukup mumpuni, namun tetap belum dapat mengantisipasi time budget pressure.

\section{SIMPULAN}

Beberapa simpulan yang didapatkan dari hasil penelitian ini adalah sebagai berikut :

1. Time budget pressure atau tekanan waktu anggaran terbukti berpengaruh negatif terhadap kualitas audit.

2. Pengalaman auditor terbukti berpengaruh positif terhadap kualitas audit.

Implikasi teoritis dari penelitian ini adalah bahwa diperlukan riset-riset selanjutnya untuk meneliti determinan penentu terjadinya time budget pressure agar upaya-upaya dalam mencegah atau meminimalisirnya juga dapat ditemukan. Sementara implikasi praktis yang didapatkan dari penelitian ini adalah bahwa persaingan jasa audit di DKI Jakarta yang tinggi cenderung mengakibatkan besarnya time budget pressure sehingga kualitas auditnya relatif akan menurun. Selain itu, pengalaman auditor akan menjadi bagian penting untuk menghasilkan kualitas audit yang mumpuni. KAP dan para pemangku kebijakan diharapkan dapat memberikan pelatihan dan pembekalan khusus kepada para auditor agar dapat mengantisipasi resiko time budget pressure.

\section{DAFTAR PUSTAKA}

Agustin, A. (2013). Pengaruh Pengalaman, Independensi, dan Due Profesional Care Auditor Terhadap Kualitas Audit Laporan Keuangan Pemerintah. Pengaruh Pengalaman, Independensi, Dan Due Profesional Care Auditor Terhadap Kualitas Audit Laporan Keuangan Pemerintah, 1-24.

Aisyah, E. A., \& Sukirman. (2015). Hubungan Pengalaman, Time Budged Pressure, Kompensasi terhadap Kualitas Audit pada Kantor Akuntansi Publik (KAP) di Kota semarang. Accounting Analysis Journal, 4(1), 1-11. 
Andreas. (2016). Interaction between Time Budget Pressure and Professional Commitment towards Underreporting of Time Behavior. Procedia - Social and Behavioral Sciences, 219, 91-98. https://doi.org/10.1016/j.sbspro.2016.04.047

Anugrah, I., Kamaliah, K., \& Ilham, E. (2017). Pengaruh TIME Budget Pressure, Kompetensi dan Independensi terhadap Kualitas Audit dengan Etika Profesi sebagai Variable Moderasi. Jurnal Online Mahasiswa Fakultas Ekonomi Universitas Riau, 4(1), 13221336.

Arisinta, O. (2013). Pengaruh Kompetensi, Independensi, Time Budget Pressure, dan Audit Fee Terhadap Kualitas Audit pada Kantor Akuntan Publik di Surabaya. Jurnal Ekonomi Dan Bisnis, 3, 266-278.

Asante-Appiah, B. (2019). Does the severity of a client's negative environmental, social and governance reputation affect audit effort and audit quality? Journal of Accounting and Public Policy. https://doi.org/10.1016/j.jaccpubpol.2019.106713

Ayuningtyas, H. Y., \& Pamudji, S. (2012). Pengaruh Pengalaman Kerja, Independensi, Obyektifitas, Integritas Dan Kompetensi Terhadap Kualitas Hasil Audit (Studi Kasus Pada Auditor Inspektorat Kota/Kabupaten di Jawa Tengah). Fakultas Ekonomika dan Bisnis.

Cita Dewi, A. A., \& Ramantha, I. W. (2019). Pengaruh Profesionalisme dan Time Budget Pressure Pada Kualitas Audit Dengan Fee Audit Sebagai Variabel Pemoderasi. E-Jurnal Akuntansi, 26, 563. https://doi.org/10.24843/eja.2019.v26.i01.p21

Desi, F., \& Dhini, P. (2014). Pengaruh Time Budget Pressure Terhadap Kualitas Audit Dengan Independensi Sebagai Variabel Intervening (Studi Kasus Pada Bpk Ri Perwakilan Provinsi Daerah Istimewa Yogyakarta). Accounting Analysis Journal, 3(4), 446-456. https://doi.org/10.15294/aaj.v3i4.4206

Elizabeth, V., \& Laksito, H. (2017). Pengaruh TIME Budget Pressure terhadap Kualitas Audit dan Budaya Etis sebagai Variabel Mediator. Pengaruh Time Budget Pressure Terhadap Kualitas Audit Dan Budaya Etis Sebagai Variabel Mediator, 6(3), 101-110.

Futri, P. S., \& Juliarsa, G. (2014). Pengaruh Independensi, Profesionalisme, Tingkat Pendidikan, Etika Profesi, Pengalaman, dan Kepuasan Kerja Auditor pada Kualitas Audit Kantor Akuntan Publik di Bali. E-Jurnal Akuntansi Universitas Udayana, 7(2), 444-461. https://doi.org/10.1111/j.1365-2761.1986.tb01041.x

Maulina, M., Anggraini, R., \& Anwar, C. (2010). Pengaruh Tekanan Waktu Dan Tindakan Supervisi Terhadap Penghentian Prematur Atas Prosedur Audit. Simposium Nasional Akuntansi.

Muhsyi, A. (2013). Pengaruh Time Budget Pressure Risiko Kesalahan Dan Kompleksitas Terhadap Kualitas Audit. Universitas Islam Negeri Syarif Hidayatullah.

Nasution, I. (2013). Pengaruh Karakteristik Personal Auditor, Etika Audit dan Pengalaman Auditor Terhadap Tingkat Penyimpangan Perilaku dalam Audit.

Ningsih, A. P. R. C. (2013). Pengaruh Kompetensi, Independensi, dan Time Budget Pressure Terhadap Kualitas Audit. E-Jurnal Akuntansi, 92-109.

Nurhayati, E. (2015). Pengaruh Pengalaman , Independensi , Dan Time Budget Pressure Terhadap Kualitas Audit Dengan Etika. Jrka, 1(2), 16-27. 
Oktarini, K., \& Ramantha, I. (2016). Pengaruh Pengalaman Kerja Dan Kepatuhan Terhadap Kode Etik Pada Kualitas Audit Melalui Skeptisisme Profesional Auditor. E-Jurnal Akuntansi, 15(1), 754-783.

Prasita, A., \& Adi, P. H. (2007). Pengaruh kompleksitas audit dan tekanan anggaran waktu terhadap kualitas audit dengan moderasi pemahaman terhadap sistem informasi. Jurnal Ekonomi Dan Bisnis, 13(1), 54-78.

Purnamasari, D., \& Hernawati, E. (2017). Pengaruh Etika Auditor, Pengalaman, Pengetahuan Dan Perilaku Disfungsional Terhadap Kualitas Audit. Jurnal NeO-Bis, 7(2), 1-17.

Putri, P. A., \& Laksito, H. (2013). Pengaruh Lingkungan Etika, Pengalaman Auditor Dan Tekanan Ketaatan Terhadap Kualitas Audit Judgment. Pengaruh Lingkungan Etika, Pengalaman Auditor Dan Tekanan Ketaatan Terhadap Kualitas Audit Judgment, 2(2001), 383-393.

Samsi, N., Riduwan, A., \& Suryono, B. (2013). Pengaruh Pengalaman Kerja, Independensi Dan Kompetensi Terhadap Kualitas Audit: Etika Auditor Sebagai Variabel Pemoderasi. Jurnal Ilmu Dan Riset Akuntansi, 1(2), 207-226.

Siagian, O., \& Meutia, I. (2016). Pengaruh Time Budget Pressure, Kompleksitas Tugas dan Kompetensi terhadap Kualitas Audit dengan Supervisi Audit sebagai Variabel Moderasi ( Studi Empiris Pada Perwakilan BPKP Provinsi Sumatera Selatan ). Akuntabilitas: Jurnal Penelitian Dan Pengembangan Akuntansi, 10(1), 55-78.

Sun, J., Wang, J., Kent, P., \& Qi, B. (2020). Does sharing the same network auditor in group affiliated firms affect audit quality? Journal of Accounting and Public Policy, 39(1), 106711. https://doi.org/10.1016/j.jaccpubpol.2019.106711

Suprianto, E. (2009). Pengaruh Time Budget Pressure Terhadap Perilaku Disfungsional Auditor (Audit Quality Reductian Behavior, Prematur Sign-Off \& Under Reporting Of Time)(Studi Kasus pada Kantor Akuntan Publik di Jawa Tengah). JAI Volume, 5(1), 5765 .

Suraida, I. (2005). Pengaruh etika, kompetensi, pengalaman audit dan risiko audit terhadap skeptisisme profesional auditor dan ketepatan pemberian opini akuntan publik. Sosiohumaniora, 7(3), 186.

Suryo, M. (2017). Pengaruh Time Budget Pressure Dan Risiko Audit Terhadap Kualitas Audit (Survey Pada Auditor Di Kantor Akuntan Publik Di Bandung). Jurnal Riset Akuntansi Dan Keuangan, 5(1), 1325-1336. https://doi.org/10.17509/jrak.v5i1.6757

Susetyo, B. (2009). Pengaruh Pengalaman Audit terhadap Pertimbangan Auditor dengan Kredibilitas Klien Sebagai Variabel Moderating (Survey Empiris Auditor Yang Bekerja Pada Kantor Akuntan Publik dan Koperasi Jasa Audit di Wilayah Jawa Tengah dan Daerah Istimewa Yogyakarta). UNIVERSITAS DIPONEGORO.

Trihapsari, D. A., \& Anisyakurlillah, I. (2016). Pengaruh Etika,Independensi,Pengalaman Audit Dan Premature Sign Off Terhadap Kualitas Audit. Accounting Analysis Journal, 5(1), 1-7. https://doi.org/10.15294/aaj.v5i1.9756

Wardhani, V. K., Triyuwono, I., \& Achsin, M. (2015). Pengaruh Pengalaman Kerja, Independensi, Integritas, Obyektivitas Dan Kompetensi Terhadap Kualitas Audit. Journal of Innovation in Business and Economics, 5(1), 63. https://doi.org/10.22219/jibe.vol5.no1.63-74 
Willett, C., \& Page, M. J. (1996). A survey of time budget pressure and irregular auditing practices among newly qualified UK chartered accountants. British Accounting Review, 28(2), 101-120. https://doi.org/10.1006/bare.1996.0009

Wulan, P. R., \& Primasari, N. H. (2017). Pengaruh Pengalaman, Independensi dan Due Professional Care Terhadap Kualitas Audit. 133-146.

Xiao, T., Geng, C., \& Yuan, C. (2020). How audit effort affects audit quality: An audit process and audit output perspective. China Journal of Accounting Research, 13(1), 109-127. https://doi.org/10.1016/j.cjar.2020.02.002

Yaniartha S., P. (2013). Pengaruh Kompetensi, Independensi, Dan Time Budget Pressure Terhadap Kualitas Audit. E-Jurnal Akuntansi, 4(1), 92-109. 